\title{
KONSTRUKSI TEKNOLOGI JEJARING SOSIAL DALAM PENINGKATAN AKSES INFORMASI RUMAH IBADAH
}

\author{
Heriyanto \\ Sekolah Tinggi Agama Buddha Negeri Sriwijaya Tangerang Banten \\ heriyanto@stabn-sriwijaya.ac.id.
}

\begin{abstract}
Tujuan kajian adalah mendeskripsikan bagaimana konstruksi teknologi jejaring sosial dalam peningkatan akses informasi rumah ibadah. Data-data dikumpulkan melalui berbagai pustaka, seperti buku-buku dan sumber referensi lain baik primer dan skunder. Untuk selanjutanya metode analisis yang digunakan adalah konten analisis, dengan penjabaran secara deskriptif dan menarasikan kembali. Hasil kajian mendeskripsikan teknologi jejaring sosial seperti facebook dan twitter serta segala fasilitas yang dimiliki dapat digunakan untuk mempermudah akses informasi keluar dan kedalam rumah ibadah. Vihara dan Cetiya dapat menggunakan berbagai fasilitas yang ada pada facebook dan twitter untuk mengatasi permasalahan akses informasi. Status, komentar, notes, docs, share, chatting, iklan, promosi, lokasi, event, messanger, follower, following, mentions, dan hashtag dapat digunakan untuk melakukan sharing informasi dan mendapatkan informasi bagi Vihara dan Cetiya sehingga bermanfaat terhadap perkembangan dan kemajuan rumah ibadah keagamaan khusunya Vihara dan Cetiya.
\end{abstract}

Keyword: Jejaring Sosial, Social Networking, Facebook, Twitter, Akses Informasi

\section{A. Pendahuluan}

Perkembangan Teknologi Informasi dan komunikasi dewasa ini berkembang sangat pesat. Teknologi Informasi dan komunikasi telah menjadi bagian yang tak terpisahkan dari kehidupan masyarakat. Hasil perkembangan Teknologi Informasi dan komunikasi yang sangat terkenal dan relevan masa sekarang adalah Internet dan Social Networking. Social Networking merupakan bentuk media sosial yang diaplikasikan dengan media baru dalam bentuk situs jejaring sosial seperti Facebook, Twitter, Google ${ }^{+,}$Youtube, MySpace, LinkedIn, Tumblr, Istagram, dan masih banyak lagi. Pengguna internet akhir tahun 2013 di Indonesia mencapai 63 juta orang. Dari angka tersebut, 95 persennya menggunakan internet untuk mengakses jejaring sosial. Situs jejaring sosial yang paling banyak diakses adalah Facebook dan Twitter ${ }^{1}$. Indonesia menempati peringkat 4 (empat) pengguna Facebook terbesar setelah USA, Brazil, dan India. Sedangkan untuk pengguna Twitter, Indonesia menempati peringkat 5 (lima) setelah USA, Brazil, Jepang dan Inggris ${ }^{2}$.

Penggunaan jejaring sosial dalam berbagai bidang kehidupan masyarakat untuk meningkatkan akses informasi, komunikasi, dan sosial menjadi kajian hangat akhirakhir ini. Situs jejaring sosial juga dapat menjadi wadah untuk mencari teman dan wadah komunikasi tanpa harus bertatap muka. Pola penggunaan facebook dan twitter adalah berbagai informasi, hiburan, kelompok pertemanan, dan komunitas. Kenyataan

\footnotetext{
${ }^{1}$ Selamatta Sembiring . 2013. Pengguna Internet di indinesia mencapai 63 Juta.

${ }^{2}$ www.kominfo.go.id. 2013.

http://kominfo.go.id/index.php/content/detail/3415/Kominfo+\%3A+Pengguna+Internet+di+Indonesia+63 + Juta+Orang/0/berita_satker\#.U6U4ULEYtK0
} 
sekarang, facebook dan twitter juga menjadi bagian dalam berbagai bidang kehidupan masyarakat. Pendidikan, gaya hidup, hiburan, sosial, dan juga bidang keagamaan tidak lepas dari penggunaan media sosial seperti facebook dan twitter.

Kehadiran jejaring sosial membawa dampak perubahan aktivitas berkomunikasi. Dalam bidang keagamaan, dewasa ini account facebook dan twitter dimiliki oleh berbagai yayasan, lembaga, organisasi keagamaan, dan rumah ibadah. Masjid, Gereja, Pura, Vihara, dan Kelenteng hampir seluruhnya memiliki account facebook dan twitter untuk berbagai kepentingan, tentunya tidak lepas dari kepentingan sharing dan akses informasi. Jejaring sosial membentuk pola komunikasi baru dimasyarakat dengan kekuatan menghilangkan jarak, ruang ,dan waktu. Bagaimana teknologi jejaring sosial seperti facebook dan twitter membawa dampak dalam peningkatan akses informasi dan komunikasi rumah ibadah menjadi permasalahan tersendiri. Pencarian lokasi peribadatan disuatu daerah menjadi masalah klasik umat dalam mencari rumah ibadah. Perubahan signifikan proses penyebaran pesan menjadi bagian dari era modern seperti sekarang, tetapi informasi update dan tepat waktu yang seharusnya diterima umat masih saja sulit diterima dan jauh dari harapan.

Kesulitan akses informasi baik keluar maupun kedalam organisasi menjadi permasalahan umum masyarakat. Tidak terlepas rumah ibadah juga memiliki permasalah tersendiri berkaitan dengan akses informasi. Penggunaan teknologi internet tidak menjadi alat untuk mengatasi kesulitan akses informasi tetapi hanya menjadi wadah dan tempat untuk hiburan dan eksistensi semata. Di Indonesia penggunaan jejaring sosial seperti facebook dan twitter lebih banyak digunakan untuk hal-hal yang tidak produktif, yang sebenarnya dapat digunakan untuk sesuatu yang bermanfaat. Kemampuan jejaring sosial untuk mendistribusikan segala konten atau informasi dari media yang sedang dibangun tidak dimanfaatkan rumah ibadah untuk mengatasi permasalahan akses informasi. Seiring perkembangan jejaring sosial, seperti facebook dan twitter kini telah dilengkapi dengan fasilitas pencarian (searching) yang dapat memberikan hasil berupa teks, foto, maupun video. Pada kenyataan, fasilitas tidak dimanfaatkan sebagai alat untuk penyebaran informasi, fasilitas tersebut lebih banyak digunakan untuk melakukan upload foto-foto pribadi dan alat untuk menampilkan exsistensi diri.

Berangkat dari permasalahan yang ada, kajian ini hanya dikhususkan membahas konstruksi teknologi jejaring sosial dalam peningkatan akses informasi rumah ibadah Agama Buddha (Vihara dan Cetiya). Tujuan kajian adalah mendeskripsikan bagaimana konstruksi teknologi jejaring sosial dalam peningkatan akses informasi rumah ibadah. Hasil kajian diharapkan memberikan kontribusi sumbangan teoritis berkaitan dengan pemanfaatan jejaring sosial oleh rumah ibadah khusunya Vihara dan Cetiya. Manfaat praktis hasil kajian dapat digunakan sebagai bahan masukan dan arah kebijakan pemanfaatan teknologi jejaring sosial dalam peningkatan akses informasi rumah ibadah. Hasil kajian juga memberikan masukan bagi para pengurus rumah ibadah dan pengambil keputusan dalam menerapkan teknologi jejaring sosial untuk digunakan mendukung akses informasi rumah ibadah.

\section{B. Kajian Teori}

\section{Jejaring Sosial}

Internet memiliki berbagai jenis layanan yang diwujudkan dalam berbagai bentuk, mulai portal berita hingga situs jejaring sosial. Situs jejaring sosial adalah suatu 
media atau sarana untuk berbagi data atau informasi personal, di mana dalam beberapa situs jejaring sosial terbuka untuk semua orang, dan ada pula yang dibatasi oleh rentang umur tertentu ${ }^{3}$. Situs jejaring sosial menjadi wadah untuk mencari teman dan wadah komunikasi tanpa harus bertatap muka dengan memanfaatkan fasilitas internet. Situs jejaring sosial merupakan sebuah situs berbasis pelayanan yang memungkinkan penggunanya untuk membuat profil, melihat list pengguna yang tersedia, serta mengundang atau menerima teman untuk bergabung dalam situs tersebut ${ }^{4}$. Tampilan dasar situs jejaring sosial ini menampilkan halaman profil pengguna, yang di dalamnya terdiri dari identitas diri dan foto pengguna serta dapat menampilkan kronologi dan aktivitas pengguna.

Situs jejaring sosial memiliki daya tarik dan layanan yang berbeda, namun pada dasarnya tujuan jejaring sosial sama yaitu untuk berkomunikasi dengan mudah dan lebih menarik karena ditambah fitur-fitur yang memanjakan penggunanya. Situs jejaring sosial merupakan layanan berbasis web dimana digunakan untuk bersosialisasi dan berkomunikasi dengan pihak lain baik dengan teman, keluarga, maupun suatu komunitas yang memiliki tujuan yang sama. Jejaring sosial juga dapat menghubungkan pengguna dengan banyak orang yang mengguankan jejaring sosial tersebut. Berhubung dengan teman, keluarga, menambah teman baru, menampilkan aktivitas, upload foto, teks, video, dan juga melakukan pencarian (search).

\section{Facebook}

Facebook merupakan salah satu layanan jaringan sosial internet tanpa harus membayar untuk mendaftar, dan dapat membentuk jaringan sosial dengan mengundang teman. Facebook dapat diakses pada www.facebook.com. Dengan Jaringan dibentuk, dapat memberikan akses untuk memperhatikan aktifitas teman, mengikuti game yang direkomendasikan, menambahkan teman atau jaringan berdasarkan kriteria tertentu seperti organisasi, sekolah, daerah domisili, kesamaan hobi dan fans. Facebook memberikan kesempatan berteman dan membina kehidupan sosial.

Facebook didirikan pada 4 Februari 2004 oleh Mark Zuckerberg. Misi facebook adalah untuk memberi orang kekuatan berbagi dan membuat dunia lebih terbuka dan terhubung. Menggunakan facebook untuk tetap terhubung dengan teman dan keluarga, untuk menemukan apa yang terjadi di dunia, dan untuk berbagi mengungkapkan apa yang penting dan layak diketahui orang banyak. Layanan facebook terdiri dari fitur update status dan comment wall-to-wall, note atau docs pada group, fitur share link/ photo/ video, group chatting dan messenger, Kronologi aktivitas, online games, fungsi iklan dan promosi, fungsi karir, funsi

\footnotetext{
${ }^{3}$ Mann, B. L. 2008. Social Networking Website - A Concatenation of Impersonation, Denigration, Sexual Aggresive, Solicitation, Cyber- Bullying or Happy Slapping Videos. International Journal of Law and Technology Information, Volume 17 (3), 252-267. Oxford University Press.

${ }^{4}$ Firmansyah, Aditya. (2010). "Situs Jejaring Sosial Menggunakan Elgg.” Makalah tidak diterbitkan. Sekolah Teknik Elektro dan Informatika. ITB. Bandung.
} 
lokasi, facebook page, fungsi hobi, event, upload file, developper widget, mobile access dan browsing ${ }^{5}$.

\section{Twitter}

Twitter adalah sebuah situs jejaring sosial yang dimiliki dan dioperasikan oleh Twitter Inc., twitter menawarkan jejaring sosial berupa mikroblog sehingga memungkinkan penggunanya untuk mengirim dan membaca pesan yang disebut kicauan (tweets). Twitter diresmikan pada tanggal 19 April 2007. Misi twitter memberikan kemampuan kepada setiap orang untuk membuat dan membagi ide dan informasi secara cepat, tanpa hambatan. Tweet adalah teks tulisan hingga 140 karakter yang ditampilkan pada halaman profil pengguna. Tweet bisa dilihat secara luar, namun pengirim dapat membatasi pengiriman pesan ke daftar temanteman. Semua pengguna dapat mengirim dan menerima Tweet melalui situs Twitter, aplikasi eksternal yang kompatibel (mobile), atau dengan pesan singkat (SMS) yang tersedia di negara-negara tertentu.

Tweet twitter mampu tersebar ke seluruh dunia kepada teman terhubung dengan kecepatan sepersekian detik melalui kode hashtag (\#), juga tidak memiliki prosedur keamanan yang rumit. Layanan twitter meliputi layanan bisnis, layanan media, dan layanan pengembang. Istilah dalam twitter meliputi profil, tweet, follower, following, mentions, direct message, hashtag, list, dan trending topic ${ }^{6}$

\section{Akses informasi}

Informasi merupakan hasil pengolahan data sehingga menjadi bentuk yang penting bagi penerimanya dan mempunyai kegunaan sebagai dasar dalam pengambilan keputusan yang dapat dirasakan akibatnya secara langsung saat itu juga atau secara tidak langsung pada saat mendatang (Sutana, 2003:10). Persyaratan informasi harus memenuhi unsur dapat dipercaya, relevan, bernilai, dan tepat waktu. Informasi juga dapat dikatakan bentuk yang lebih berguna dan berarti bagi penggunanya. Hak mendapatkan informasi dan berkomunikasi menjadi bagian yang terpisahkan dari hak pribadi yang telah termuat dalam HAM (Hak Asasi manusia) (UUD RI 1945 pasal 28 F).

Akses merupakan cara bagaimana seseorang mendapatkan sesuatu. Dalam kaitannya dengan informasi, akses informasi merupakan cara mendapatkan dan berbagi informasi yang dapat dilakukan dengan berbagai cara menggunakan alat dan bahan bahkan dengan dukungan teknologi yang sedang berkembang. Dukungan teknologi informasi menjadikan proses memperoleh informasi yang diperlukan untuk mengembangkan pribadi dan lingkungan sosial menjadi semakin mudah.

\section{Metode Kajian}

Kajian konstruksi teknologi jejaring sosial dalam peningkatan akses informasi rumah ibadah menggunakan metode konten analisis. Analisi isi dilakukan dengan analisis mendalam dari sumber-sumber relevan yang kemudian dideskripsikan dan dinarasikan dalam bentuk hasil kajian. Pada kajian ini, wawancara dan observasi

\footnotetext{
${ }^{5}$ Facebook.com. info. https://www.facebook.com/facebook/info

${ }^{6}$ Twitter.com. About. https://about.twitter.com/id.
} 
lapangan juga dilakukan pada subjek dan objek yang menjadi kajian untuk memperkuat data dan analisis.

\section{Pembahasan}

Situs jejaring sosial mampu membentuk jaringan pertemanan dan diskusi yang sangat kuat. Jejaring sosial menjadi wadah untuk mencari teman dan wadah komunikasi tanpa harus bertatap muka dengan memanfaatkan fasilitas internet. Layanan facebook dan twitter dapat diimplementasikan rumah ibadah untuk meningkatkan akses informasi rumah ibadah khususnya Vihara dan Cetiya.

1. Implementasi Facebook dalam Peningkatan Akses Informasi Rumah Ibadah

Pertama sekali, dengan membuat dan memiliki account facebook Vihata dan Cetiya dapat mengundang pertemanan dan melakukan promosi account. Account facebook Vihara dan Cetiya memungkinkan seluruh umat dan bahkan teman-teman yang terhubung dari umat Vihata dan Cetiya lain akan terhubung, dalam hal ini menjadi pertemanan dalam jejaring sosial facebook. Selanjutnya fungsi-fungsi facebook dapat dimanfaatkan sebagai dukungan Vihara dan Cetiya dalam menyebar dan mencari informasi.

\section{a) Update Status dan Comment Wall-to-wall}

Fitur ini merupakan interaksi dua arah, komunikasi terdokumentasi berdasar topik bahasan dan terurut secara waktu (kronologi). Vihara dan Cetiya dapat memanfaatkan fungsi ini sebagai sarana memberikan informasi kegiatan yang akan dilakukan. Informasi kegiatan, pengumuman, dan segala informasi yang diharapkan diterima oleh umat dan masyarakat dapat dikirimkan sebagai status yang dituliskan melalui wall account facebook. Status dapat berupa pesan teks, gambar, audio, vedeo, dan bahkan link (alamat situs pada internet). Dengan kemampuan tersebut, tentunya update status akan sangat baik dilakukan tanpa harus memiliki biaya transfortasi, administrasi serta Alat Tulis Kantor (ATK) dengan biaya besar. Update status lokasi juga dapat dilakukan, memungkinkan informasi lokasi keberadaan suatu tempat sehingga mudah dicari dan dikunjungi.

Status berlangsung dua arah, komentar dapat diberikan oleh penerima dan seluruh teman yang terhubung dapat menanggapi melalui fasilitas komentar pada status. Dengan fungsi tersebut memungkinkan terjadinya diskusi, tanya jawab, dan bahkan membentuk percakapan yang panjang mengenai topik status. Vihara dan Cetiya dapat menggunakan status untuk mengirimkan dan sharing pesan-pesan keagamaan, sutta-sutta, dhammapada, informasi kebaktian dan penceramah. Selanjutnya umat dan seluruh teman terhubung dapat menanggapi dan memberikan komentar terkait status yang di share. Suasana dan forum diskusi antar teman akan terjadi dan berlangsung dua arah. Diskusi yang mendalam menjadikan pemahaman dan memberikan kontribusi pengetahuan. Informasi menjadi jelas, dan diterima tepat waktu oleh umat. Begitu juga sebaliknya status umat dan teman yang terhubung melalui account facebook Vihara dan Cetiya akan dapat terlihat dan menjadi masukan informasi, manajemen, dan kebijakan organisasi keagamaan khusunya Vihara dan Cetiya. 
b) Note dan Docs pada Group

Note dan Docs pada Group dapat digunakan untuk menulis catatan dan membuat dokumen. Catatan dapat dilengkapi dengan fasilitas gambar dan juga pengaturan privasi. Menu aplikasi notes dapat ditambahkan melalui menu yang berada di bawah photo cover, jika belum tersedia dapat ditambahkan dengan melakukan klik more lalu pilih notes. Fasilitas notes dapat digunakan sebagai sarana menuangkan pemikiran, gagasan, informasi, dan berita terbaru.

Rumah ibadah dapat menggunakan notes dan docs untuk pembabaran dan penyebaran Dharma. Menuliskan dan menyebarkan sutta-sutta Sang Buddha melalui tulisan dan dokumen yang dapat dikirimkan dan dikomentari oleh seluruh umat. Berita dan informasi Vihara dan Cetiya dapat dituliskan melalui notes dan docs. Keunggulan notes dan docs yaitu file dapat terindeks oleh search engine (mesin pencari) Google, sehingga memberikan keuntungan tersendiri bagi eksistensi Vihara dan Cetiya tersebut pada dunia internet, yang berujung pada informasi Vihara dan Cetiya yang semakin mudah dicari.

c) Share link, photo, dan video

Kemampuan facebook sebagai media sosial semakin meningkat dengan fasilitas share link, photo, dan video. Dengan melakukan sharing memungkinkan untuk berbagi berita dan informasi menjadi semakin mudah. Foto kegiatan Vihara dan Cetiya akan semakin mudah diterima oleh umat, dokumentasi pada event dan kegiatan tertentu akan tersebar dengan mudah. Foto dan video juga dapat dikirimkan khusus pada orangorang tertentu yang menginginkan. Fasilitas Share link/ photo/ video menjadi alat marketing yang dapat dipegang oleh admin Vihara dan Cetiya. Dokumentasi pelaporan pembangunan dalam bentuk foto dan video juga dapat dikirimkan pada donatur pembangunan. Foto dan video lebih menyenangkan dan banyak disukai, dan mampu meyampaikan pesan lebih efektif. Fasilitas Share link/ photo/ video menjadi media yang dapat dengan mudah menyampaikan informasi yang akan dikirimkan Vihara dan Cetiya pada penerima.

d) Group chatting dan messenger

Fasilitas Group chatting dan messenger ada pada facebook versi desktop (komputer) dan pada smartphone (mobile). Facebook Messenger adalah aplikasi chat mirip Yahoo Messenger atau Skype. Pertemanan, berdiskusi, kirim mengirim pesan akan semakin mudah. Group chatting dan messenger dapat menggantikan fungsi sms dan telepon. Dengan menggunakan smartphone kirim mengirim pesan akan semakin mudah. Koordinasi dan komunikasi pengurus Vihara dan Cetiya akan semakin mudah. Informasi rapat, event tertentu, bakti sosial, sampai pada informasi kebaktian, pemberkatan umat, dan informasi lowongan kerja dari sesama umat Vihara dan Cetiya akan menjadi mudah diberitahukan. 
e) Fungsi iklan, promosi, fungsi lokasi, dan fungsi Event

Untuk mengiklankan informasi bahkan untuk kepentingan pribadi dan organisasi, fungsi iklan dapat digunakan. Fungsi lokasi memberikan informasi keberadaan sebuah tempat ibadah sehingga semakin mudah dicari dan dikunjungi. Internet menjadi dunia tersendiri di dalam dunia nyata, melakukan iklan dan promosi serta share lokasi banyak memberikan keuntungan tersendiri untuk mendatangkan para pengunjung mengatahui dan berdatangan.

Fasilitas event (acara) dapat digunakan sebagai cara mengundang temanteman untuk menghadiri acara yang akan diselenggarakan, baik itu pernikahan, perayaan hari besar agama seperti Waisak, Maghapuja, Asadha, dan khatina. Fitur event dapat mempermudah informasi acara dan kegiatan serta melakukan penghematan biaya yang digunakan untuk biaya transfortasi dan pendistribusian undangan.

2. Implementasi Twitter dalam Peningkatan Akses Informasi Rumah Ibadah

Twitter membantu membuat dan berbagi ide dan informasi secara cepat tanpa hambatan dengan menggunkan fasilitas internet. Dengan memiliki account twitter rumah ibadah khusunya Vihara dan Cetiya akan sangat mudah mendapatkan dan menyebarkan pesan dalam bentuk tweet. Tweet dapat berisi teks, foto, dan video.

Implementasi akses informasi keluar rumah ibadah dapat dilakukan dengan kekuatan follower, dengan mengizinkan pengguna lain untuk mengikuti account rumah ibadah dan memungkinkan setiap tweet dapat mereka terima. Dengan menjadikan seluruh umat Vihara dan Cetiya menjadi follower, memungkinkan berbagai informasi yang ingin di share oleh Vihara dan Cetiya akan sangat dengan mudah mereka terima dan berada pada halaman home follower. Berbagai berita, kegiatan, foto, dan video dapat di tweet oleh Vihara dan Cetiya untuk sampai pada umat. Lebih lanjut semakin banayaknya follower maka akan semakin mudah informasi diterima oleh masyarakat luas. Informasi kegiatan Vihara dan Cetiya akan dengan mudah dibagikan dan diceritakan peristiwa demi peristiwa kepada seluruh follower.

Mendapatkan tweet yang menarik, dapat dilakukan dengan menjadi follower account lain. Implementasi mendapatkan akses informasi kedalam dapat dilakukan dengan menjadi follower account lain dengan tweet yang berkualitas. Informasi perayaan hari raya keagamaan, koordinasi rumah ibadah, informasi bakti sosial, sekolah minggu, dan permasalahan umat akan dapat diterima dengan cepat dan mudah. Informasi umum dapat diterima dengan menjadi follower sumber-sumber berita, selebritis, menjalin pertemanan dengan account Vihara dan Cetiya lain, lembaga-lembaga keagamaan, dan juga dapat dilakukan dengan menjalin petemanan dengan institusi pendidikan keagamaan, tentunya melalui perteman dan jejaring sosial twitter.

Percakapan pribadi dengan follower lain dapat dilakukan tanpa diketahui teman lainnya melalui direct message. Direct message juga dapat dikatakan dengan private message, jadi meskipun memberikan kemudahan untuk akses 
informasi keluar dan kedalam rumah ibadah tetapi tingkat privasi dan keamanan tetap terjaga. Untuk setiap tweet yang diberikan sesama pertemanan dapat melakukan percakapan dan menanggapi. Mentions (dengan tanda @) adalah istilah balasan dari percakapan dan diskusi agar para pengguna dapat langsung menandai sesama teman yang akan di ajak berbicara. List adalah pengelompokan following pengguna kedalam suatu grup, dapat digunakan untuk menyatukan anggota Vihara dan Cetiya, atau dengan kata lain pengelompokan untuk mempermudah melakukan tweet kepada sesama anggota Vihara dan Cetiya hanya pada kelompok yang diinginkan.

Facebook dan twitter memiliki fungsi dengan nama hashtag. Fungsi hashtag pada facebook dan juga twitter adalah untuk memudahkan penggunanya mengikuti dan melihat topik tertentu yang diinginkannya. Ketika hashtag disertakan pada sebuah kata dalam sebuah postingan (berupa status, artikel, video, gambar, teks, notes, dan event) maka dengan mengklik kata yang diberi hashtag tersebut akan menampilkan postingan penggguna lain yang menggunakan hashtag yang sama. Fungsi ini dapat diigunakan untuk mencari dan pengelompokan konten (isi) yang diinginkan. Dalam memberikan informasi event, account rumah ibadah dapat menyertakan hashtag pada event tersebut agar semua update tentang event yang dibuat akan terorganisir dan terkelompok dengan baik. Sehingga mereka yang mengikuti event yang dibuat dapat mengetahui perkembangan sebuah event. Bagi mereka yang tidak mengikuti event tersebut namun tertarik mengikuti perkembangannya, mereka dapat mengetikan hashtag tentang event untuk mengetahui update terbaru tentang event.

Fitur hashtag dan mentions untuk membuat konten atau update status lebih kaya informasi dan bermanfaat. Kemudian mentions dapat dilakukan pada profile atau sebuah page (halaman) dengan mengetikan @ didepan nama profile atau page teman yang akan di mention. Dengan demikian obrolan akan menjadi lebih bertema, menarik, dan bermanfaat.

\section{E. Kesimpulan}

Teknologi jejaring sosial seperti facebook dan twitter serta segala fasilitas yang dimiliki dapat digunakan untuk mempermudah akses informasi keluar dan kedalam rumah ibadah. Vihara dan Cetiya dapat menggunakan berbagai fasilitas yang ada pada facebook dan twitter untuk mengatasi permasalahan akses informasi. Status, komentar, notes, docs, share, chatting, iklan, promosi, lokasi, event, messanger, follower, following, mentions, dan hashtag dapat digunakan untuk melakukan sharing informasi dan mendapatkan informasi bagi Vihara dan Cetiya sehingga bermanfaat terhadap perkembangan dan kemajuan rumah ibadah keagamaan khusunya Vihara dan Cetiya.

Diharapkan kemajuan dan perkembangan teknologi khususnya jejaring sosial tidak digunakan hanya sebagai alat eksistensi, melainkan digunakan untuk membawa perkembangan, keuntungan, dan menjadi alat pendukung akses informasi yang berguna bagi pengambilan keputusan, kebijakan, manajemen, dan dukungan penuh terhadap operasional rumah ibadah. 


\section{F. Referensi}

Firmansyah, Aditya. 2010. Situs Jejaring Sosial Menggunakan Elgg. Makalah tidak diterbitkan. Sekolah Teknik Elektro dan Informatika. ITB. Bandung.

Kementerian komunikasi dan informatika Republik Indonesia. Pengguna Internet di Indonesia 63 Juta orang.

http://kominfo.go.id/index.php/content/detail/3415/Kominfo+\%3A+Pengguna+Int ernet+di+Indonesia+63+Juta+Orang/0/berita_satker\#.U6U4ULEYtK0 (diakses 12 Maret 2014).

Mann, B. L. 2008. Social Networking Website - A Concatenation of Impersonation, Denigration, Sexual Aggresive, Solicitation, Cyber- Bullying or Happy Slapping Videos. International Journal of Law and Technology Information , Volume 17 (3), 252-267. Oxford University Press

Selamatta Sembiring . 2013. Pengguna Internet di indinesia mencapai 63 Juta. http://kominfo.go.id/index.php/content/detail/3415/Kominfo+\%3A+Pengguna+Int ernet+di+Indonesia+63+Juta+Orang/0/berita_satker\#.U6U4ULEYtK0 (diakses 12 Maret 2014).

www. Twitter.com. 2014. https://about.twitter.com/id (diakses 11 Mei 2014).

www.facebook.com. 2014. https://www.facebook.com/facebook/info (diakses 27 Mei 2014). 